\title{
Curriculum System of Engineering Education: Quality Standards and Function Integration
}

\author{
Jiaming Sun \\ South China Normal University Guangzhou, China \\ 236852899@qq.com \\ Correspondence Author:Sun Jiaming,Shaoguan University, Shaoguan, China.
}

\begin{abstract}
Key words: Engineering Education at Undergraduate Level; Curriculum Quantity; Curriculum Quality; Curriculum Function

Abstract: Engineering education is the "intersection" of the two systems, engineering and education, of which there are both common characteristics of general education and characteristics of engineering. The curriculum system of engineering education at undergraduate level takes curriculum quantity as the foundation, the curriculum quality as the core and curriculum functions are the guarantee, the interaction and mutual influence of them constitute the three-dimensional images of the curriculum system. The curriculum system of mutual check and balance has gone through the evolution process with spiral rise from equilibrium state $\rightarrow$ non-equilibrium state $\rightarrow$ new equilibrium state, so as to ensure the stable, orderly, dynamic and benign development of the curriculum system.
\end{abstract}

\section{Introduction}

In the face of fierce social changes, emergence of new science and technologies, changes in students' backgrounds and interests and other issues, where does the engineering education in the 21 st century stays, where is the final destination and whether it is still in the crossroad with no signs?

《The Engineering that Changes the World》was once pointed out :" today the majority of universities are trying to train engineers for the 21 st century with a set of courses in the $20^{\text {th }}$ century in a $19^{\text {th }}$ century school." The work for future engineers is unknown. The engineering education at undergraduate level is faced with the problem how to solve fundamental contradiction between the uncertainty of external demands and the limitation of the educational system. The curriculum system, as the fulcrum of engineering education reform, is the carrier for personnel training of engineering education. This paper carries out an analysis from the perspective of microcosmic on the number of courses that needs to be set for majors of engineering, methods to build the engineering paradigm curriculum system and strategies to make periodic two-year or four-year adjustment for the curriculum system. Therefore, the reconstruction of the curriculum system of engineering education at undergraduate level is the basic research topic for engineering education reform, which is related to the quality of engineers in the future, the development of new industrialization, the construction of innovative country and the implementation of the strategy of strengthening the nation by talents.

\section{The Curriculum Standards of Engineering Education: Curriculum Quality}

\section{(I) The Quantitative Comparison: Curriculum Quantity}

The adjustment mechanism for curriculum quantity of engineering education is manifested mainly through the internal and external relations in higher education. On the external conditions, "the influence of social development and scientific progress on higher education is played through majors ...and curriculum plays the fundamental functions, or ultimately colleges echo the development of science and technology, the economic, political and cultural progress and changes through curriculum." ${ }^{[1]}$ It forces curriculum quantity of engineering education at undergraduate level and contents to experience the process of expansion, contraction, deletion, transferring and elimination through the contact with the outside world. On the internal conditions, all kinds of undergraduate colleges and universities become suppliers of the combination of different goods and services package and curriculum quantity based on their training orientation and mode of engineering talents, while the students gradually develop into the role of curriculum consumers. In theory, the more quantity and variety of engineering education courses the universities offer, the 
better they can meet the more diversified curriculum choice of undergraduates and the more likely the engineers fit the market demands. It is no wonder that some scholars believe better universities can be said to be those able to provide more and better courses ${ }^{[2]}$

(1) From the perspective of the development trend of engineering education curriculum, there is a tendency of increase in elective courses but relative decrease in compulsory courses. The quantity relationship of the curriculum system of engineering education is mainly reflected in the credit proportion between elective courses and compulsory courses, which can be measured by curriculum density and curriculum concentration. Curriculum Density refers to the proportion that the credits for elective courses take up in the total credits, which can reflect the proportion of elective courses. In engineering education, the more credits for elective courses and greater curriculum density indicate that the quantitative structure of curriculum system may be more reasonable. Curriculum Concentration refers to the proportion that the credits for compulsory courses take up in total credits, which can be used to measure the proportion of compulsory courses. The fewer credits for compulsory courses in engineering education and smaller curriculum concentration indicate that quantitative structure of curriculum system may be more optimized.

(2) From the perspective of the development of elective system of engineering education curriculum, it is inevitable to expand the degree of freedom for students to select courses. The quantitative relationship of elective curriculum structure can be reflected by examining the freedom in curriculum choice of engineering education to seek the balance between the restrictive elective courses and the non-restrictive elective courses. The restrictive elective courses of engineering education refers to selecting courses in the research fields of majors of engineering, which mainly provide major (direction) diversion service for colleges and pursues the professional core knowledge structure and the professional development dimension of engineers; the non-restrictive elective courses refer to these elective courses set up mainly based on needs of society, discipline and student development, which point at the diversified development of engineers in the future and personalized learning freedom. Curriculum Selection Freedom means the ratio of non-restrictive elective courses in the total credits of elective courses. The larger proportion of credits of non-restrictive elective courses, the wider range and the finer levels mean the greater freedom of course selection. (Fig. 1.)

Curriculum Density of Engineering Education = credits for elective courses / total credits

Engineering Concentration of Engineering Education = credits for compulsory courses / total credits

Freedom of Course Selection of Engineering Education = credits for non-restrictive elective

Fig. 1: The Scope of Quantitative Relationship of Curriculum System of Engineering Education

(II). The Qualitative Comparison: Curriculum Quality

(1) Objectives of curriculum of engineering education

The undergraduate engineering education aims to train qualified professional engineers, but there is big difference in the training objectives of engineers among different countries and different types and levels of universities, with different emphases. ABET puts forward the personnel training standards from 11 aspects for undergraduate engineering education. ${ }^{[3]}$ FEANI proposes 12 standards for the ability of engineers. ${ }^{[4]}$ In the certification standards for engineering education major developed by JABEE there are 7 requirements on capacity. ${ }^{[5]}$ The CEEAA certification standards can be divided into two parts, general standards and professional supplementary standards, of which the general standards cover three aspects of the training objectives and provides 12 graduation requirements to support the completion of training objectives. ${ }^{[6]}$ Specifically, it is the characteristics of the ABET standards to require that engineering and non-technical capacities should be treated equally; FEANI standards focus on the internal association between engineering and economy, society, ethics, law, technology and other areas; the JABEE standards lie stress on the application ability of technology and knowledge as well as global thinking ability. CEEAA emphasizes the discipline, specialty and integrality of curriculum, with a separate system for each discipline. 
Therefore, the training objectives of undergraduate engineering education should be supported by corresponding curriculum system, while the premise of curriculum reform should be the division of diverse types of engineer training and the establishment of course goals based on the training objectives of engineer.

The curriculum of traditional engineering education seems like the game of "bag grabbing". The various courses are dissociated like the Atomic Theory Curriculum, as a result, although students have completed all the courses and got the required credits, they have not formed a more integrated concept of knowledge or a more comprehensive, more realistic concept of life. ${ }^{[7]}$ The curriculum system of engineering education is connected based on the strong or weak causal association between the significance and knowledge of curriculum to optimize the internal links among the subsystems of a single course, build courses network topology, gather the disperse single courses and generate a cumulative effect, making it possible for the engineering education content to become a systematic and coherent whole. It can also be said that the curriculum system of engineering education is a concrete manifestation of professionals training programs. Therefore, the curriculum system of engineering education reflects the professional knowledge structure and ability system, while the professional knowledge structure and ability system make up the course system. In time of judging whether the curriculum system of majors of engineering is reasonable and optimized, it becomes the question that to what extent can a systematic course matric be established based on the association of significance and knowledge, that is, optimizing the knowledge inheritance and delivery of engineering education courses to the fullest extent and extending the effective points in the knowledge chain of engineering education curriculum system. There mainly are three aspects involved: (1) whether there is association among various single courses; (2) How is the degree of correlation among the single courses; (3) What is the logical relationship existing among these courses?

From the perspective of sources of curriculum resources, "any single source of information is not enough to provide a basis for judiciously and comprehensively determining the school objectives." ${ }^{[8]}$ For determining the curriculum objectives of engineering education, the first thing is to clarify cohesive relations between curriculum and educational objectives and training objectives in order to ensure that these requirements can be reflected in the curriculum. Second, the effective curriculum objectives can only be determined on the basis of an in-depth study on the characteristics of students, social needs, discipline development and other aspects. ${ }^{[9]}$ Therefore, the development of curriculum objectives of engineering education should take the training types or engineer as a premise and ability development as the direction, pay attention to the needs of students, teachers, industry, certification bodies and other stakeholders, insist on the combination education and profession and finally develop curriculum objectives of presumption of optimal relevance among knowledge, ability and qualities of engineers.

\section{(2) The curriculum concepts of engineering education}

(1)The internal integration of science education and humanistic education.

The emphasis of science education is to cultivate scientific spirit, enhance scientific literacy and train scientific and technical talents; however, humanistic education puts emphasis on the cultivation of humanistic spirit, promotion of human nature, shaping of ideal personality and realization of individual values. For a long time, humanities education has always been overlooked in the heated pursuit of social efficiency and just set off engineering education as a "green leaf". However, "without humanities education, technologies are not complete, while humanities education will not exist without technical education ... ... Education should aim to train students into people of of great learning and great ability as well as perfect skills." ${ }^{[10]}$ It is advocated in modern engineering education that there should be organic integration between positive results of the ideological trend that science is sovereign and service for practical projects to reverse the situation of excessive emphasis on science and deviation from engineering practice and fundamentally solve the problem of "technically narrow engineering education" and "engineering education narrow in technology". However, such integration will not cause differences in functions with the increase and decrease of the proportion between the variety and quantity of engineering education courses, 
because the scientific and humanistic tendency of engineering education is more embodied in the teaching process of single courses.

(2) The unity of general education and professional education.

The curriculum of general education attaches importance to the comprehension of knowledge, ability and quality in personnel training; curriculum of professional education lays a foundation for students to prepare themselves for their future career, and highlights the systematic and normative nature of the professional knowledge itself. Since the 1960s, the educational concepts of engineering education in America has gone through the development track from traditional technology paradigm to the research science paradigm and then to the "Engineering with a big E" education. This modern engineers training returning to engineering shall not only have the ability to solve problems in engineering practice related to technical factors ("Hard Strength"), but also have the abilities related to teamwork, communication, ethics and other non-technical factors ("Soft Power"). In comparison, the personnel training model of engineering education at undergraduate level in our country is mainly "professional education" and characterized by "de-engineering". Therefore the engineering talents have the tendency of "blank". In fact, "for disciplines, there should be relative fields and for occupation, there should be appropriate division. It is not right to seek just basic knowledge, without expertise. People with only expertise but no basic knowledge cannot get a sound understanding when analyzing and solve problems, resulting into weak adaptability; those who understand only a little about each discipline and are satisfied with a smattering of knowledge are also difficult to achieve anything."[11] There is not a competitive relationship between them, but non-zero and game relationship. Otherwise, the utilitarian concept of engineering education curriculum will lead to professionalism and vocationalism and eventually lead to the acquired incomplete of complex engineering and technical personnel.

\section{(III) The principle of engineering education curriculum}

(1) Sequence principle. According to the vertical organization sequence of curriculum, it is necessary to pay attention to both the logical organization of knowledge and significance and the law of the psychological significance of the students' backgrounds among all single courses. It is believed in the recapitulation theory of education that the learning process of modern students is a cognitive recapitulation of the development process of human culture. In other words, the cognitive development of modern people is the enrichment of the long-term evolution of their ancestors' cognitive level. In addition to the engineering perspective, the thought transformation of curriculum reform for engineering education must have another important structural ability-for orderly change. The "Order" refers to the connection modes for regular arrangement of elements of things, while "the orderly change does not refer to the continuous changes in the sense of time but logic, the related changes in relationship in the curriculum system." ${ }^{[12]}$ Therefore, the internal unity of logical order and psychological order can only be developed by optimizing the breadth and depth of the content of engineering education courses from the perspective of disciplinary systems and cognitive processes, handling the time sequence and context of the curriculum structure, and division of labor and collaborative resonance of curriculum subsystems.

(2) Integrity principle. Based on the horizontal organizational sequence of the curriculum, "Integrity is the key to the effectiveness and efficiency of curriculum delivery." ${ }^{[13]}$ Because of the various characteristics of engerining such as multidimensional nature of social backgrounds, the complexity of problem settlement, the process in the life cycle of engineering products and the systematicness of engineering activity stages, for the curriculum setting of modern engineering education, the fragmentation projects divided by disciplines need to be reduced to a whole to form the "overall optimization law" of the curriculum system (namely, the whole function is more than the sum of partial functions), get rid of the limit of reductive style of thinking and train engineers with 'perfect' images, including the intelligence and wisdom of Lillian Gilbreth, the problem settlement ability of Gillon Moore, the scientific insight of Albert Einstein, the creativity of Pablo Picasso, the decisiveness of Wright brothers, the leadership of Bi11 Gates, the moral heart of Eleanor Roosevelt, the vision of Martin Luther King and the curiosity of children." ${ }^{[14]}$

(3) Relevance principle. On one hand, the curriculum reform of engineering education can not 
be separated from the external environment, and the expectations from social forces on curriculum have such a great influence that they often decisively influence the relevance of the courses experienced by stakeholders. ${ }^{[15]}$ Social appeals for engineering education curriculum reform usually are expressed by stakeholders of engineering education. Curriculum reform should serve stakeholders, while stakeholders can shape the curriculum. On the other hand, the difference in occupation division among different professional engineers in the engineering field causes the hysteresis of engineering education itself and always fails to develop faster than diversified work. Therefore, in the curriculum system of undergraduate engineering education, it is necessary to set up alternate application courses in combination with the orientation of colleges and training standards, deal with a variety of dilemmas such as breadth and depth of knowledge, overall choice and individual choice, local vision and international vision and others and remove the homogenization phenomenon.

(4) Measurement principle. The Outcome-Based Education(OBE) is an important basis for the development of teaching objectives of various courses of engineering education as well as an important content of engineering professional certification standards. Its core lies in ensuring the graduates can meet the established quality standards recognized in the engineering industry, which is a type of curriculum evaluation with training objectives and graduation requirements as a guide. Based on the graduation requirements, the training objectives are designed backward to develop the training standards system, with positive implementation of training programs, assessment and continuous improvement process to build the "capacity development- professional courses" matrix. The expected learning outcomes are clear, not ambiguous. OBE curriculum setting is measured based on curriculum objectives mapping expected learning outcomes, or it is impossible to determine whether the objectives of single course are achieved or not. Therefore, as a pre-course management, it can measure the achievement degree of curriculum objectives through the decomposition of knowledge structure and ability system of a single course, to establish curriculum thinking map and realize the transformation from imparting engineering knowledge into training ability required by occupations.

\section{(IV) Content of engineering education curriculum}

(1)From disconnection to integration: the relationship between Theoretical Courses and Practical Courses. Since its origins, the engineering education has been carrying two genes of "engineering" and "education" and trying find a balance between the two parts of "practice" and "theory" with the development of engineering education. This phenomenon leads to two kinds of engineering education curriculum models: knowledge-based curriculum model which takes learning systematic engineering theoretical knowledge as the center and emphasizes the system and integrity of disciplines; ability-based curriculum model which takes developing engineers' ability as the center and pays attention to the practice and application of curriculum. However, in reality, they show attachment, segregation, and convergence disruptions in curriculum status and implementation. For example, in February 2013, a survey of employers in the industrial field showed that as many as $93 \%$ of employers believed that the curriculum deviated from engineering practice, among whom $19 \%$ of all employers selected serious deviation. It confirmed that the reality that China's undergraduate engineering education has seriously deviated from engineering practice. Mao Yisheng once proposed the reference model of "learning by practicing" and he believed that the object of practice is practice itself while the object of learning is theory. "Theory and practice should serve as the basis and tool for each other, rather than completion or isolation. Because of this, in engineering learning theory is not necessarily prior to practice and if practice coming first leads to better effect, it is necessary to abandon the prejudice that theory should be the basic." ${ }^{[16]}$ Thus the theoretical courses with indirect experience as the core and the practical courses with direct experience as the core can not be replaced by each other, even be neglected.

(2)From platter to integration: the relationship between Subject Curriculum and Integrated Curriculum. "In life scenes there is no clear sign which aspects belong to sociology, history, economics or politics."[17] Therefore, the subject curriculum and integrated curriculum are two curriculum organization forms with complementary functions, of which subject curriculum 
focuses on the vertical, logical and independent nature of subject knowledge, while integrated curriculum focuses on the horizontal, rich and connected nature of subject knowledge. Modern engineering education practice is characterized by systemic, complex, diversified, global and sustainable development. The interdisciplinary and mutual infiltration of art and science make the knowledge boundary of engineering education more and more fragile. Professor Domenico Grasso puts forward the "holistic view of engineering, which in short refers to more interdisciplinary, full-system communication skills for engineering; In the fast-changing world, the emphasis is placed on the context, with the leadership of the team as the leader of the team and the desire for lifelong learning." ${ }^{[18]}$ This "subtraction thinking" in the integration of sub-curriculum is intended to improve the integration and holism of the curriculum: namely, the implementation of projects courses of different integration level in more fields (PjBL), process-oriented curriculum (CDIO), and school-enterprise cooperation curriculum (Co-op) and other bridging curriculum forms to achieve the goal of solving practical problems by using interdisciplinary knowledge and cause the "Medici effect."

(3)From Consensus to Complementation: the relationship between Compulsory Courses and Elective Courses. Since the middle of 19th century, although the elective course system has become an important indicator of modern university teaching management, the proportion of compulsory and elective courses and the relationship between them have not reached the same consensus like the elective system. For example, in the Department of Mechanical Engineering, the proportion of elective courses in Massachusetts Institute of Technology was $40.91 \%$, but that in Shanghai Jiao Tong University was $22.87 \%$, which means a difference of 18 percentage. ${ }^{[19]}$ Then how many compulsory courses and elective courses should be set for the majors of engineering? The most perfect ratio seems to lie between the complete compulsory and complete elective system, and specifically, according to academic development, vocational preparation and other standards, in the classification and reorganization of elective courses, it should be a trend that the proportion of elective courses is slightly larger than the compulsory courses in curriculum reform of engineering education. Of course, it is necessary to avoid extreme mistakes like the "hodgepodge" course overloading and "superficial" learning process.

(4)From Separation to Penetration: the relationship between Explicit Courses and Recessive Courses. They are not in a mainstay and auxiliary relationship, instead, they are interactive and complementary and mutually transformational. In the 1960s, American scholar PWJackson in 《The Classroom Life》 formally put forward the concept, believed that recessive curriculum is the key to success for every teacher and student in school, and explicitly put forward the idea that explicit courses and recessive courses formed the main body of school curriculum together. The curriculum concept of traditional engineering education focuses on explicit curriculum and pays attention to the systematization of all disciplines, while ignoring the recessive curriculum, but the recessive courses may have a positive or negative effect. Therefore, the curriculum reform of modern engineering education should take into account both engineering benefits and engineering ethics, which should reform and enrich the explicit curriculum and play the positive function of the recessive curriculum. Vividly speaking, the explicit curriculum is the fertile soil for engineers, while recessive curriculum is the rain and sun for engineers. There should be mutual invasion and dipping the tension of the functions.

(5)From Deficiency to Dissolving: the relationship between Innovative Curriculum and Entrepreneurial Curriculum. The innovative curriculum aims to cultivate students' innovative consciousness and skills to carry out creative design and product development, solve specific problems and strengthen the quality of innovation; the entrepreneurial curriculum aims at cultivating students' entrepreneurial awareness and skills in exploiting market opportunities and customer needs, practicing entrepreneurship and strengthening entrepreneurship quality. It is shown in 2015 Chinese College Students Employment Report that the proportion of graduates that start their own businesses continues to rise, but the 2014 graduates have only $2.9 \%$ that start their own businesses, of which the proportion of engineering graduates that start their own business is relatively high, because in fact, engineering students' initiative and pioneering spirit and 
entrepreneurship education is still weak. Therefore, the innovation and entrepreneurship education should be integrated into the overall background of general education and professional education to cultivate engineers of originality, rather than the employment training to address the survival problems. For example, the engineering education reform based on entrepreneurship education in the United States Franklin Olin Institute proposes the Olin Triangle for engineering education: the traditional engineering education at the top, which should be the core of engineer training; entrepreneurship education and humanities and social art education are the wings for engineer cultivation. ${ }^{[20]}$ Therefore, innovation is the foundation and core of entrepreneurship and entrepreneurship is the embodiment of innovation. The logical relationship between them should be innovation as the main body and entrepreneurship as a tool.

\section{Curriculum Functions of Engineering Education: Curriculum Measurement}

The curriculum structure determines functions, while the curriculum functions react against curriculum structure. The contradictory movement between these two constitutes the driving force of curriculum system adjustment. The optimization degree of engineering education curriculum system directly affects the size, direction and level of curriculum functions. Of course the curriculum structure is closely related to the curriculum quality. Therefore, the relationship between curriculum system of engineering education and functions will be transformed into the relationship among curriculum quantity $(\mathrm{N})$, course quality $(\mathrm{Q})$ and curriculum function $(\mathrm{F})$. From the point of view of $\mathrm{M} 1$ function, there is a decreasing function between $\mathrm{N}$ and $\mathrm{F}$, and when $\mathrm{N}$ becomes increasingly large (namely, it is complex), F shows a decreasing trend, and vice versa. From M2 function, there is an increasing function relationship between $Q$ and $F$, when $Q$ becomes increasingly bigger (namely, it is fine), F shows a rising trend (Fig. 2).

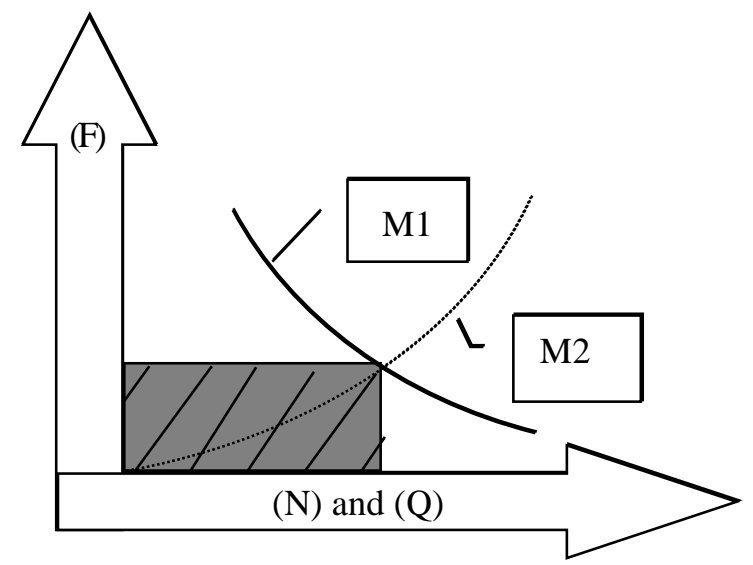

\section{Fig. 2:The Functional Relationship among Quantity, Quality and Function of Engineering Education Curriculum}

As an open self-organizing system, the undergraduate engineering education curriculum system has exchange of resources through the external environment and in the meanwhile the curriculum quantity and qualitative elements also will be slightly adjusted, with curriculum functions playing a virtuous role of cultivating engineers. Actually, as a part of the curriculum system, each course has a specific status in the professional training program and shows a special and proper curriculum niche. When internal elements of the engineering education curriculum system changes, there will be conjugation effect on curriculum functions. The excess or shortage of curriculum supply will lead to contradiction of curriculum demand, and the curriculum structure will move from the initial equilibrium state to the non-equilibrium state. In a certain period of time, maintaining a relatively stable structure and function, the bearing capacity allowed by the curriculum structure of engineering education can be expressed by he maximum internal force or the internal force considered as unable to continue bear the deformation; when the outside stimulation goes beyond the limit for curriculum structure and function, the ultimate bearing capacity of curriculum structure can be regarded as the threshold born by curriculum structure in time of fundamental qualitative change of the core structure of curriculum system. The ultimate bearing capacity can be regarded as the critical point of coordination between its function and the external environment. Currently, 
curriculum structure system shows a movement trajectory from non-equilibrium state to a new equilibrium state, and the quantity, nature and functions of curriculum form an optimized intersection area through fundamental changes to generate a new curriculum structure system of engineering education and ensure the stable, orderly, dynamic and benign development of curriculum system. In general, the curriculum structure of engineering education has gone through the periodic adjustment process of spiral rising from equilibrium state $\rightarrow$ non-equilibrium state $\rightarrow$ new equilibrium state, which has promoted the balance between curriculum structure supply and course demand.

\section{Conclusion}

The purpose is not to analyzes elements of the curriculum system of undergraduate engineering education, but to find its adjustment mechanism of the dynamic evolution process, incorporate it into the overall background of politics, economy, culture and society, study the relationship among these elements from horizontal and vertical comparison, breadth and depth, structure and function and other aspects and clearly define that curriculum quantity is the foundation, curriculum quality is the core and curriculum function is the guarantee. The curriculum reform of undergraduate engineering education is to reconstruct the cultivation program of the regression project in accordance with the training objectives and related training environment and to strengthen the validity of curriculum quality and highlight the development of the overall curriculum functions through the integration of quantity of curriculum system category. At present, China has been in the transition from big country with manufacturing industry to powerful manufacturing country and from big country with engineering education to powerful engineering education country, so it is necessary to establish human resources in line with the strategic transformation of manufacturing industry, promote the structural reform of supply side for engineer development and improve the adaptability to changes in external demand. Therefore, the engineering education requires curriculum and the mission of curriculum lies in educating.

\section{References}

[1] ZHANG Chuting. University and Curriculum [J]. Journal of Higher Education. 2003 (2): 73-77. [2] Zhang Chuting. Higher Education Philosophy [M]. Changsha: Hunan Education Press, 2004, Page 298.

[3] ABET.Criteria for Accrediting Engineering Programs 2010-2011[R].Accreditation Board for Engineering and Technology,2009: P2-5.

[4] FEANI. Competence of Professional Engineers /EUR ING[EB/OL]. http://www. feani. org /webfeani/.

[5] ECUK. The Accreditation of Higher Education Programmes[EB/OL].http://www. engc. org. uk/.

[6] CEEAA. Common Criteria.[EB/OL].http://cn.ceeaa.org.cn/index.php.

[7] Ernest- L. Boyer: Speech on American Education Reform [M]. Translator: Tu Yanguo, Fang Tong. Beijing: Educational Science Press, 2002, Page 23.

[8] Ralph W.Tyler.Basic Principles of Curriculum and Instruction.[M].Chicago and London: the University of Chicago Press,1949.P5.

[9] Shi Liangfang. Curriculum Theory [M]. Education Science Press, 2000, Page 93

[10] White. On the Purpose of Education[M]. Translator: Li Yonghong, Beijing: Educational Science Press, 1997, Page 241.

[11] Pan Maoyuan. Lectures on Higher Education [M]. Beijing: People's Education Press, 1993, Page 12.

[12] Gong Yizu, Chen Wanming. University Curriculum System Construction and Resource Allocation[J]. Higher Education Research. 2005 (10): 53-57.

[13] Gaff JG.,etal.Handbook of Undergraduate Curriculum:A Comprehensive Guide to Purposes, Structures, Practices, and Change[M].San Francisco:Jossey-Bass Publisher, 1997.P702. 
[14] NAO Engineering.The Engineer of 2020:Visions of Engineering in the New Century[M]. Washington DC: National Academy of Engineering.2004.P53-57.

[15] Forrest. W. Parker, et al. Contemporary Curriculum Planning (8th Edition.) [M]. Translator: Sun Defang. Beijing: Renmin University of China Press, 2010, Page 55.

[16] Shi Guiquan. China Modern Higher Engineering Education Research[M]. Shanghai: Shanghai Jiaotong University Press, 2004, Page 183.

[17] John Brubeck. The philosophy of Higher Education[M]. Hangzhou: Zhejiang Education Press, 1987: Page 102.

[18] Domenico Grasso, Melody Brown Burkins. Beyond Technology: The Holistic Advantage[A].Holistic Engineering Education. Spring, 2009: 1-2.

[19] Gong Yu, Chen Min. Comparison of Undergraduate Curriculums in Higher Engineering Education between China and the United States-A Case Study of Shanghai Jiaotong University and Massachusetts Institute of Technology[J]. University Research and Evaluation; 2009(6): Page 86-90 .

[20] Xu Xiaozhou, Zang Lingling. The Integration of Entrepreneurship Education and Engineering Education - An Analysis on Educational Mode of Olin Institute of Technology[J]. Research in Education of Higher Engineering, 2010 (1): 103-107. 